\title{
Atributos físico-hídricos de um Latossolo após a aplicação de lodo de esgoto em área degradada do Cerrado
}

\author{
Hydro-physical attributes of an Oxisol after sewage sludge application on a Cerrado \\ degraded area
}

\author{
Fabiana da Silva de Campos ${ }^{\mathrm{I}}$ Marlene Cristina Alves $^{\mathrm{I}}$ Zigomar Menezes de Souza $^{\mathrm{II}}$ \\ Gener Tadeu Pereira ${ }^{\text {II }}$
}

\section{RESUMO}

Os solos cultivados intensivamente $e$ inadequadamente são degradados, assim como a construção de obras civis no meio rural executada sem atender à legislação. O trabalho objetivou definir a interferência do lodo de esgoto na recuperação de atributos de um Latossolo Vermelho. $O$ experimento foi implantado em 2004, em Selviria (MS). Os tratamentos utilizados foram: $T_{1}$-vegetação de cerrado; $T_{2}-$ solo exposto sem tratamento para recuperação; $T_{3}$-solo cultivado com eucalipto e braquiária sem o uso do lodo de esgoto e adubação mineral; $T_{4}$-solo cultivado com eucalipto e braquiária com adubação mineral; $T_{5}$-solo cultivado com

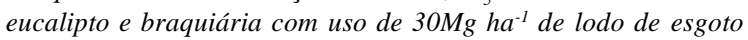
e; $T_{6}$-solo cultivado com eucalipto e braquiária com uso de $60 \mathrm{Mg} \mathrm{ha} \mathrm{h}^{-1}$ de lodo de esgoto. Nas camadas do solo de 0,000,05; 0,05-0,10; 0,10-0,20 e de 0,20-0,30m, foram avaliados os atributos físico-hídricos e teor de matéria orgânica. Os tratamentos com adubação mineral e orgânica estão agindo de forma semelhante para a recuperação dos atributos físicohídricos e do teor de matéria orgânica. Em solos degradados pela construção de obras civis a aplicação de 30 a $60 \mathrm{mg}$ de lodo de esgoto ha-1 recupera as suas propriedades físico-hídricas.

Palavras-chave: degradação do solo, recuperação do solo, eucalipto, braquiária, matéria orgânica do solo.

\section{ABSTRACT}

Intensively and inadequately managed soils and the civil construction industry in the rural area that are unconcerned with specific legislation, result in several problems in the environment. The objective of the present study was to evaluate the influence of sewage sludge on the recovery of hydro-physical properties of an Oxisol. The experiment was implanted in 2004, in Selviria, Mato Grosso do Sul, Brazil. The six experimental treatments were arranged according to a randomized complete-block design with four replications. The experimental treatments were: 1 - Native Cerrado vegetation; 2 - degraded soil without treatment for soil recovery; 3 Eucalyptus citriodora planting and Brachiaria decumbens sowing and no sewage sludge or mineral fertilization use; 4 Eucalyptus citriodora planting and Brachiaria decumbens sowing in soil enriched with mineral fertilizer; 5 - Eucalyptus citriodora planting and Brachiaria decumbens sowing in soil

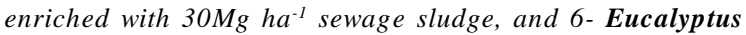
citriodora planting and Brachiaria decumbens sowing in soil enriched with $60 \mathrm{Mg} \mathrm{ha}^{-1}$ sewage sludge. Hydro-physical properties and the soil organic matter content were characterized at 0.00-to-0.05;0.05-to-0.10;0.10-to-0.20 and 0.20-to-0.30m layers in the soil. Mineral and organic fertilization treatments showed similar effects on the recovery of the hydro-physical properties and organic matter content of the degraded soil. The hydro-physical properties and organic matter content of Cerrado soils degraded due to civil construction activities can be recovered by the use of 30 to $60 \mathrm{Mg}$ sewage sludge $\mathrm{ha}^{-1}$.

Key words: soil degradation, soil recovery, eucalyptus, pasture, organic matter.

\section{INTRODUÇÃO}

A reciclagem agrícola de lodo representa uma alternativa para minimizar o problema de disposição final desse material, bem como prevenir contra efeitos

\footnotetext{
'Departamento de Fitossanidade, Engenharia Rural e Solos, Faculdade de Engenharia, Universidade Estadual Paulista (UNESP), Campus de Ilha Solteira, CP 31, 15385-000, Ilha Solteira, SP, Brasil. E-mail: mcalves@agr.feis.unesp.br. *Autor para correspondência. "Faculdade de Engenharia Agrícola, Universidade Estadual de Campinas (UNICAMP), Campinas, SP, Brasil.

IIIFaculdade de Ciências Agrárias e Veterinárias (FCAV), Campus de Jaboticabal, UNESP, Jaboticabal, SP, Brasil.
} 
adversos no ambiente, prezando pela conservação dos recursos naturais e por benefícios agronômicos. O lodo de esgoto pode melhorar os atributos físicos do solo, pois favorece a formação de agregados do solo, com a consequente melhoria na infiltração da água no perfil, a retenção de água e a aeração do solo, e causa reflexos ambientais imediatos, como a redução da erosão (SOUZA et al., 2005).

Além da degradação do solo pelo uso agrícola, a construção de obras civis no meio rural também tem acarretado problemas de degradação ambiental, como, por exemplo, a construção de reservatórios, onde diversas áreas podem apresentar degradação, que se manifestam pelo desequilíbrio da litosfera (sobretudo em sua porção mais frágil, os solos), a hidrosfera e a biosfera (principalmente a cobertura vegetal). A recuperação desse tipo de ambiente é necessária para a minimização do impacto causado (ALVES et al., 2007). A adição de material orgânico no processo de recuperação do solo pode promover uma melhoria na sua estrutura, alterando favoravelmente a proporção de agregados estáveis em água.

Em solos tropicais, onde a matéria orgânica desempenha papel de fundamental importância, em que os seus níveis são geralmente baixos, a utilização do lodo de esgoto torna-se uma alternativa para a elevação de seus teores, especialmente em solos degradados (TRANNIN et al., 2008).

De acordo com DE MARIA et al. (2007), estudando a agregação de solo em área submetida à aplicação de lodo de esgoto, o resíduo tratado com polieletrólitos, incorporado ao solo nas doses de $10 \mathrm{e}$ $20 \mathrm{Mg} \mathrm{ha}^{-1}$, proporcionou o aumento no teor de matéria orgânica e na estabilidade dos agregados do solo na camada $0,00-0,10 \mathrm{~m}$, após duas aplicações anuais consecutivas. Já SOUZA et al. (2005), observaram o aumento do diâmetro médio dos agregados com aplicação de $50 \mathrm{Mg} \mathrm{ha}^{-1}$ em Latossolos.

Segundo PALADINI \& MIELNICZUK (1991), dentro do universo das plantas, as gramíneas têm exercido maiores benefícios à estruturação do solo. Esses efeitos benéficos são atribuídos, principalmente, à alta densidade de raízes, que promove a aproximação de partículas pela constante absorção de água do perfil do solo, às periódicas renovações do sistema radicular e àuniforme distribuição dos exsudatos no solo, que estimulam a atividade microbiana, cujos subprodutos atuam na formação e estabilização dos agregados.

No caso do eucalipto, além das utilizações de seus produtos florestais, as plantações podem também servir a uma variedade de propósitos, tais como a produção de mel, ornamentação, recuperação de áreas degradadas, proteção de bacias hidrográficas, como quebra-ventos, e vários outros usos. O presente trabalho teve como objetivo definir a interferência do lodo de esgoto na recuperação de atributos físicoshídricos de um Latossolo Vermelho degradado.

\section{MATERIAL E MÉTODOS}

O estudo foi realizado no município de Selvíria (MS), localizado nas coordenadas geográficas de $20^{\circ} 22^{\prime}$ sul e $51^{\circ} 22^{\prime}$ oeste, numa altitude média de $335 \mathrm{~m}$ acima do nível do mar. O tipo climático, segundo Köppen, é Aw, caracterizado como tropical úmido com estação chuvosa no verão e seca no inverno, e umidade relativa dos meses mais chuvosos entre 60 e $80 \%$. SegundoDEMATTÊ (1980) e EMBRAPA (2006), o solo decapitado da área de estudo foi classificado como Latossolo Vermelho Distrófico, textura franco-argilo arenosa. A caracterização física e química do solo da área experimental foi realizada em dezembro de 2002, antes da implantação do experimento (Tabela 1).

O delineamento experimental utilizado foi $o$ de blocos casualizados, com 6 tratamentos e 4 repetições, instalados em fevereiro de 2003. Os tratamentos foram: $\mathrm{T}_{1}$-vegetação natural de Cerrado; $\mathrm{T}_{2}$-solo degradado, sem tratamento para recuperação; $\mathrm{T}_{3}$-solo degradado, cultivado com eucalipto e braquiária, sem aplicação de lodo de esgoto e adubo mineral; $\mathrm{T}_{4}$-solo degradado, cultivado com eucalipto e braquiária com adubação mineral de acordo com a necessidade da cultura e a análise do solo (Tabela 2), sendo as quantidades de adubos aplicadas: $20 \mathrm{~kg} \mathrm{ha}^{-1}$ de N, $90 \mathrm{~kg} \mathrm{ha}^{-1}$ de $\mathrm{P}_{2} \mathrm{O}_{5}$ e $20 \mathrm{~kg} \mathrm{ha}^{-1}$ de $\mathrm{K}_{2} \mathrm{O}$, na linha de semeadura. Em cobertura, foram aplicados $39 \mathrm{~kg} \mathrm{ha}^{-1} \mathrm{de}$ $\mathrm{Ne} 39 \mathrm{~kg} \mathrm{ha}^{-1}$ de $\mathrm{K}_{2} \mathrm{O}$, divididos em três vezes de $13,0 \mathrm{~kg}$ ha $^{-1}$ de $\mathrm{K}_{2} \mathrm{O}$ no ano; $\mathrm{T}_{5}$-solo degradado, cultivado com eucalipto e braquiária com uso de $30 \mathrm{Mg} \mathrm{ha}^{-1}$ de lodo de esgoto (base seca); $\mathrm{T}_{6}$-solo degradado, cultivado com eucalipto e braquiária com uso de $60 \mathrm{Mg} \mathrm{ha}^{-1}$ de lodo de esgoto (base seca). Não houve a aplicação de fertilizantes na cultura da braquiária.

A dose de $60 \mathrm{mg} \mathrm{ha}^{-1}$ foi definida levando-se em consideração as dosagens de lodo que têm sido utilizadas em pesquisas com recuperação de propriedades físicas dos solos (MELO et al., 1994; VAZ \& GONÇALVES, 2002). Na literatura sobre o tema, as doses variam de 20 a $120 \mathrm{Mg} \mathrm{ha}^{-1}$.

Cada parcela ocupou uma área de $120 \mathrm{~m}^{2}$ $(12 \mathrm{~m} \times 10 \mathrm{~m})$. As parcelas com a vegetação (T1) e solo degradado (T2) encontravam-se a $100 \mathrm{~m}$ e $5 \mathrm{~m}$ dos blocos, respectivamente. As parcelas dos tratamentos T3 a T6 foram instaladas em área degradada de onde foi retirado $8,60 \mathrm{~m}$ da camada superficial do solo para utilização na terraplanagem da Usina Hidrelétrica de Ilha Solteira (SP), entre 1960 e 1978. Esta área 
Tabela 1 - Valores médios de porosidade total, macroporosidade, microporosidade, densidade do solo, distribuição de tamanho de partículas, $\mathrm{P}, \mathrm{MO}, \mathrm{pH}, \mathrm{K}, \mathrm{Ca}, \mathrm{Mg}, \mathrm{H}+\mathrm{Al}, \mathrm{Al}, \mathrm{SB}, \mathrm{CTC}$ e V para o solo degradado antes do seu preparo, em dezembro de 2002.

\begin{tabular}{|c|c|c|c|c|}
\hline \multirow{2}{*}{ Propriedade do solo } & \multicolumn{4}{|c|}{ 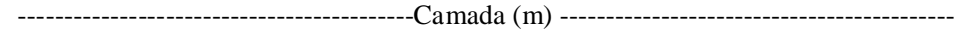 } \\
\hline & $0,00-0,05$ & $0,05-0,10$ & $0,10-0,20$ & $0,20-0,40$ \\
\hline Macroporosidade $\left(\mathrm{m}^{3} \mathrm{~m}^{-3}\right)$ & 0,08 & 0,09 & 0,08 & 0,07 \\
\hline Microporosidade $\left(\mathrm{m}^{3} \mathrm{~m}^{-3}\right)$ & 0,23 & 0,24 & 0,25 & 0,24 \\
\hline Porosidade Total $\left(\mathrm{m}^{3} \mathrm{~m}^{-3}\right)$ & 0,31 & 0,33 & 0,33 & 0,31 \\
\hline Densidade do solo $\left(\mathrm{kg} \mathrm{dm}^{-3}\right)$ & 1,70 & 1,68 & 1,68 & 1,80 \\
\hline Argila $\left(\mathrm{g} \mathrm{kg}^{-1}\right)$ & 320 & 315 & 270 & 189 \\
\hline Silte $\left(\mathrm{g} \mathrm{kg}^{-1}\right)$ & 165 & 164 & 188 & 285 \\
\hline Areia $\left(\mathrm{g} \mathrm{kg}^{-1}\right)$ & 515 & 521 & 541 & 526 \\
\hline $\mathrm{P}-$ resina $\left(\mathrm{mg} \mathrm{dm}^{-3}\right)$ & 1 & 1 & 2 & 2 \\
\hline $\mathrm{MO}\left(\mathrm{g} \mathrm{dm}^{-3}\right)$ & 5 & 4 & 3 & 3 \\
\hline $\mathrm{pH}-\mathrm{CaCl}_{2}$ & 4,5 & 4,6 & 4,7 & 4,5 \\
\hline $\mathrm{K}\left(\mathrm{mmol}_{\mathrm{c}} \mathrm{dm}^{-3}\right)$ & 0,6 & 0,1 & 0,1 & 0,1 \\
\hline $\mathrm{Ca}\left(\mathrm{mmol}_{\mathrm{c}} \mathrm{dm}^{-3}\right)$ & 4 & 4 & 4 & 3 \\
\hline $\mathrm{Mg}\left(\mathrm{mmol}_{\mathrm{c}} \mathrm{dm}^{-3}\right)$ & 2 & 2 & 2 & 2 \\
\hline $\mathrm{H}+\mathrm{Al}\left(\mathrm{mmol}_{\mathrm{c}} \mathrm{dm}^{-3}\right)$ & 15 & 15 & 15 & 15 \\
\hline $\mathrm{Al}\left(\mathrm{mmol}_{\mathrm{c}} \mathrm{dm}^{-3}\right)$ & 1 & 1 & 1 & 1 \\
\hline $\mathrm{SB}\left(\mathrm{mmol}_{\mathrm{c}} \mathrm{dm}^{-3}\right)$ & 6,6 & 6,1 & 6,1 & 5,1 \\
\hline CTC $\left(\mathrm{mmol}_{\mathrm{c}} \mathrm{dm}^{-3}\right)$ & 21,6 & 21,1 & 21,1 & 20,1 \\
\hline $\mathrm{V}(\%)$ & 31 & 29 & 29 & 25 \\
\hline
\end{tabular}

permaneceu sem manejo até quando se plantou o eucaliptus e semeou a braquiária. Em janeiro de 2003, o lodo de esgoto foi espalhado e incorporado ao solo com enxada rotativa modelo Rotavator E-60, marca FNI, largura de trabalho $1,63 \mathrm{~m}$, massa de $475 \mathrm{~kg}$.

O lodo de esgoto foi fornecido pela SANEAR (Saneamento de Araçatuba), localizada no município de Araçatuba (SP), cujo efluente é predominantemente doméstico. O lodo de esgoto apresentou a seguinte composição química média: matéria orgânica, $200 \mathrm{~g} \mathrm{dm}^{-3}$; $\mathrm{em} \mathrm{mmol}_{\mathrm{c}} \mathrm{dm}^{-3}, \mathrm{~N}, 71,26 ; \mathrm{P}$, 18,79; K, 15,14; Ca, 11,06; Mg, 3,44; S, 7,78; em mg dm${ }^{-3}$, B, 16,37; Cu, 160,04; Fe, 960,60; Mn, 115,74; Zn, 583,48; As, não detectado; em mg L L ${ }^{-1}$ Ba, 2,3; Cd, 0,003; Pb, 0,12; Cr, 0,03; Fluoretos, 1,29; Hg, não detectado; Ag, não detectado; Se, não detectado.

Em fevereiro de 2003, 30 dias após a incorporação do lodo ao solo, foi implantada a cultura do eucalipto (Eucalyptus citriodora Hook) no espaçamento $2,0 \mathrm{~m} \times 1,5 \mathrm{~m}$ nas parcelas dos tratamentos T3 a T6. Ao mesmo tempo, foi semeada nessas parcelas a braquiária (Brachiaria decumbens) a lanço nas entrelinhas, com o objetivo de contribuir para o aumento de matéria orgânica do solo e utilização da elevada quantidade inicial de $\mathrm{N}$ adicionada ao solo, em função das doses de lodo utilizadas. Não houve a aplicação de fertilizantes na cultura da braquiária.

As amostras para caracterização dos atributos físico-hídricos do solo e da matéria orgânica foram coletadas em fevereiro de 2006, após três anos da aplicação do adubo químico e do lodo de esgoto, nas profundidades de $0,00-0,05 ; 0,05-0,10 ; 0,10-0,20 \mathrm{e}$ 0,20-0,30m. Para análise da estabilidade de agregados em água, utilizou-se o método de ANGERS \& MEHUYS (1993), e os resultados foram representados por meio do diâmetro médio ponderado (DMP). As amostras de solo para avaliação da retenção de água foram coletadas usando-se anel volumétrico. A tensão mais baixa $(6,0 \mathrm{kPa})$ foi obtida na mesa de tensão, segundo metodologia proposta pela EMBRAPA (1997). Para as tensões de 50,100 e 200kPa, foi utilizada a câmara de Richards para determinar a retenção de água, seguindo a metodologia de RICHARDS (1965). Determinou-se também o teor de matéria orgânica pelo método colorimétrico, empregando-se a combustão por via úmida (EMBRAPA, 1997).

Para os atributos físico-hídricos do solo e para a matéria orgânica, realizaram-se contrastes entre a média do tratamento $\mathrm{T} 1 \mathrm{com}$ as dos demais tratamentos (vegetação natural vs. demais tratamentos); entre a média do T2 e as dos tratamentos 3, 4, 5 e 6 (solo degradado (exposto) vs. solo cultivado); entre a média do T3 e as dos tratamentos 4, 5 e 6 (solo cultivado com eucalipto e braquiária sem adubação mineral e lodo de esgoto $v s$. solo cultivado com eucalipto e braquiária e adubado); entre a média do T4 e a do $\mathrm{T}_{5}, \mathrm{~T} 6$ (adubação mineral vs. aplicação de $30 \mathrm{Mg} \mathrm{ha}^{-1} \mathrm{e} 60 \mathrm{Mg} \mathrm{ha}^{-1}$ de lodo de esgoto) e; entre a média de T5 e a de T6 (30 $\mathrm{Mg} \mathrm{ha}^{-1}$ 
Tabela 2 - Valores médios de matéria orgânica e diâmetro médio ponderado de agregados estáveis em água, para os tratamentos estudados nas camadas de $0,00-0,05 ; 0,05-0,10 ; 0,10-0,20$ e $0,20-0,30 \mathrm{~m}$.

\begin{tabular}{|c|c|c|c|c|}
\hline \multirow{2}{*}{ Tratamentos } & \multicolumn{4}{|c|}{ 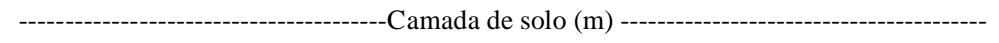 } \\
\hline & $0,00-0,05$ & $0,05-0,10$ & $0,10-0,20$ & $0,20-0,30$ \\
\hline & \multicolumn{4}{|c|}{ - } \\
\hline $\mathrm{T}_{1}-$ Cerrado & 22,25 & 12,50 & 10,25 & 9,00 \\
\hline $\mathrm{T}_{2}$ - Solo exposto & 2,00 & 1,25 & 1,25 & 1,00 \\
\hline $\mathrm{T}_{3}$. Solo s/ adubação & 5,75 & 5,25 & 4,50 & 2,00 \\
\hline $\mathrm{T}_{4}$ - Ad. Mineral & 7,25 & 5,00 & 3,75 & 2,25 \\
\hline $\mathrm{T}_{5}-30 \mathrm{Mg} \mathrm{ha}^{-1}$ & 12,25 & 8,50 & 4,25 & 2,25 \\
\hline $\mathrm{T}_{6-} 60 \mathrm{Mg} \mathrm{ha}^{-1}$ & 14,50 & 11,25 & 4,00 & 2,00 \\
\hline \multirow[t]{2}{*}{$\mathrm{CV}(\%)$} & 22,31 & 27,83 & 22,81 & 21,62 \\
\hline & \multicolumn{4}{|c|}{ 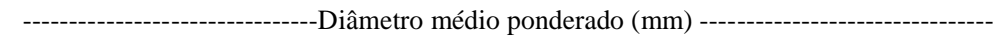 } \\
\hline $\mathrm{T}_{1}-$ Cerrado & 4,44 & 4,03 & 4,00 & 3,59 \\
\hline $\mathrm{T}_{2}$ - Solo exposto & 1,25 & 1,06 & 0,77 & 0,59 \\
\hline $\mathrm{T}_{3}$ - Solo s/ adubação & 2,35 & 2,45 & 1,51 & 0,99 \\
\hline $\mathrm{T}_{4}$ - Ad. Mineral & 2,39 & 1,57 & 1,47 & 0,81 \\
\hline $\mathrm{T}_{5-3} 30 \mathrm{Mg} \mathrm{ha}^{-1}$ & 2,52 & 1,53 & 1,24 & 0,76 \\
\hline $\mathrm{T}_{6-} 60 \mathrm{Mg} \mathrm{ha}^{-1}$ & 2,74 & 2,23 & 1,17 & 0,90 \\
\hline CV (\%) & 31,11 & 31,20 & 32,22 & 20,61 \\
\hline
\end{tabular}

$\mathrm{T}_{1}$ - vegetação natural de Cerrado; $\mathrm{T}_{2}$ - solo degradado, sem tratamento para recuperação; $\mathrm{T}_{3}$ - solo degradado, cultivado com eucalipto e braquiária, sem aplicação de lodo de esgoto e adubo mineral; $\mathrm{T}_{4}$ - solo degradado, cultivado com eucalipto e braquiária com adubação mineral de acordo com a necessidade da cultura e a análise do solo; $\mathrm{T}_{5}$ - solo degradado, cultivado com eucalipto e braquiária com uso de $30 \mathrm{mg} \mathrm{ha}^{-1}$ de lodo de esgoto (base seca); $\mathrm{T}_{6}$ - solo degradado, cultivado com eucalipto e braquiária com uso de $60 \mathrm{mg}^{-1}$ de lodo de esgoto (base seca).

de lodo de esgoto vs. $60 \mathrm{Mg} \mathrm{ha}^{-1}$ de lodo de esgoto). Os contrastes foram ortogonais e para sua análise de variância foi aplicado o teste F. Para as comparações de médias de tratamento duas a duas, foi utilizado o teste de Tukey. Ambos no nível de $5 \%$ de probabilidade.

\section{RESULTADOS E DISCUSSÃO}

Para o teor de matéria orgânica até a profundidade de $0,10 \mathrm{~m}$, todos os contrastes estudados foram significativos, com exceção do contraste $T_{5} v s$ $\mathrm{T}_{6}$ (Tabela 3). Já para a profundidade de 0,10 até $0,30 \mathrm{~m}$ somente houve significância para os contrastes $\mathrm{T}_{1} v s$ demais e $\mathrm{T}_{2} v s$ demais. Observa-se que a média do tratamento testemunha (vegetação natural de Cerrado) foi superior à média dos demais tratamentos avaliados ( $\mathrm{T}_{1} v s$ demais) até $0,30 \mathrm{~m}$ de profundidade do solo e, portanto, a aplicação de fertilizantes ou lodo de esgoto não resultou em aumentos nos teores de matéria orgânica do solo. Resultados semelhantes foram observados por ALVES et al. (2007) na recuperação de áreas degradadas por construção de hidrelétrica com adubação verde e lodo de esgoto e por ANDRADE et al. (2005), que verificaram que os teores totais de $\mathrm{C} \mathrm{e} \mathrm{N}$ em um Latossolo não foram afetados após 5 anos da aplicação de lodo de esgoto. Optou-se pela análise dos contrastes, por isso não aparecem os valores de significância na tabela 2 , na qual são apresentados os valores médios dos elementos para conhecimento do leitor.

Quando se comparou o solo exposto sem aplicação de fertilizante e lodo de esgoto aos demais tratamentos estudados ( $\mathrm{T}_{2} v s$ demais), observou-se que houve diferença estatística para a $\mathrm{MO}$ em todas as profundidades (Tabela 3 ). Os tratamentos que receberam fertilizantes, lodo de esgoto e o que não recebeu fertilizante, todos cultivados com eucalipto e na entrelinha com a braquiária, estão promovendo melhoria no teor de matéria orgânica em área degradada (Tabela 2). Resultados semelhantes foram observados por BEZERRA et al. (2006) em área em recuperação pela aplicação de lodo de esgoto. A maior parte do aumento de carbono orgânico verificado foi devida, provavelmente, à melhoria das condições de desenvolvimento das plantas, o que levou ao aumento do aporte de resíduos vegetais no solo. De acordo com ALVES \& SOUZA (2008) houve aumento no aporte de matéria orgânica no solo de área degradada por construção de hidrelétrica quando utilizada adubação verde, calagem e gesso.

Analisando-se os dados das tabelas 2 e 3 , pode-se inferir que a camada de $0,00-0,05 \mathrm{~m}$ do solo e 
Tabela 3 - Teste de significância para os contrastes entre os tratamentos referentes ao teor de matéria orgânica e aos atributos físico-hídricos do solo, para as profundidades de $0,00-0,05,0,05-0,10,0,10-0,20$ e $0,20-0,30 \mathrm{~m}$.

\begin{tabular}{|c|c|c|c|c|c|}
\hline \multirow{2}{*}{ Atributos } & \multicolumn{5}{|c|}{ 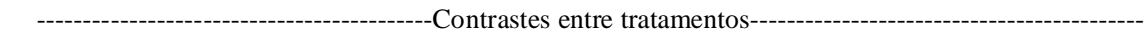 } \\
\hline & $\mathrm{T}_{1}$ vs demais & $\mathrm{T}_{2} v s$ demais & $\mathrm{T}_{3} v s$ demais & $\mathrm{T}_{4} v s \mathrm{~T}_{5} \mathrm{~T}_{6}$ & $\mathrm{~T}_{5}$ vs $\mathrm{T}_{6}$ \\
\hline & \multicolumn{5}{|c|}{ 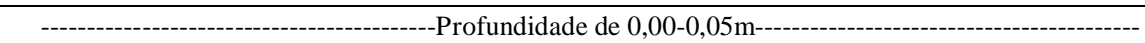 } \\
\hline${ }^{1} \mathrm{MO}\left(\mathrm{g} \mathrm{dm}^{-3}\right)$ & $*$ & $*$ & $*$ & $*$ & NS \\
\hline${ }^{2} \mathrm{DMP}(\mathrm{mm})$ & * & * & NS & NS & NS \\
\hline $50 \mathrm{kPa}\left(\mathrm{m} \mathrm{m}^{-3}\right)$ & NS & NS & NS & NS & NS \\
\hline $100 \mathrm{kPa}\left(\mathrm{m} \mathrm{m}^{-3}\right)$ & $*$ & NS & NS & NS & NS \\
\hline $200 \mathrm{kPa}\left(\mathrm{m} \mathrm{m}^{-3}\right)$ & * & NS & NS & NS & NS \\
\hline $\mathrm{MO}\left(\mathrm{g} \mathrm{dm}^{-3}\right)$ & $*$ & $*$ & $\begin{array}{l}\text { didade de } 0,05 \\
\quad *\end{array}$ & $*$ & NS \\
\hline DMP (mm) & $*$ & $*$ & NS & NS & NS \\
\hline $50 \mathrm{kPa}\left(\mathrm{m} \mathrm{m}^{-3}\right)$ & $*$ & NS & NS & NS & NS \\
\hline $100 \mathrm{kPa}\left(\mathrm{m} \mathrm{m}^{-3}\right)$ & * & NS & NS & NS & NS \\
\hline $200 \mathrm{kPa}\left(\mathrm{m} \mathrm{m}^{-3}\right)$ & $*$ & NS & NS & NS & NS \\
\hline $\mathrm{MO}\left(\mathrm{g} \mathrm{dm}^{-3}\right)$ & * & $*$ & $\begin{array}{c}\text { didade de } 0,10 \\
\text { NS }\end{array}$ & NS & NS \\
\hline DMP (mm) & $*$ & NS & NS & NS & NS \\
\hline $50 \mathrm{kPa}\left(\mathrm{m} \mathrm{m}^{-3}\right)$ & * & $*$ & NS & NS & NS \\
\hline $100 \mathrm{kPa}\left(\mathrm{m} \mathrm{m}^{-3}\right)$ & $*$ & $*$ & NS & NS & NS \\
\hline $200 \mathrm{kPa}\left(\mathrm{m} \mathrm{m}^{-3}\right)$ & $*$ & $*$ & NS & NS & NS \\
\hline $\mathrm{MO}\left(\mathrm{g} \mathrm{dm}^{-3}\right)$ & $*$ & $*$ & $\begin{array}{c}\text { didade de } 0,20- \\
\text { NS }\end{array}$ & NS & NS \\
\hline DMP (mm) & $*$ & NS & NS & NS & NS \\
\hline $50 \mathrm{kPa}\left(\mathrm{m} \mathrm{m}^{-3}\right)$ & $*$ & $*$ & NS & NS & NS \\
\hline $100 \mathrm{kPa}\left(\mathrm{m} \mathrm{m}^{-3}\right)$ & $*$ & $*$ & NS & NS & NS \\
\hline $200 \mathrm{kPa}\left(\mathrm{m} \mathrm{m}^{-3}\right)$ & $*$ & $*$ & NS & NS & NS \\
\hline
\end{tabular}

${ }^{1} \mathrm{MO}=$ teor de matéria orgânica; ${ }^{2} \mathrm{DMP}=$ diâmetro médio ponderado; $\mathrm{T}_{1}=$ Cerrado; $\mathrm{T}_{2}=$ Solo exposto; $\mathrm{T}_{3}=$ Solo s/adubação; $\mathrm{T}_{4}=$ Solo c/adubação; $\mathrm{T}_{5}=30 \mathrm{mg} \mathrm{ha}^{-1}$ de lodo de esgoto; $\mathrm{T}_{6}=60 \mathrm{mg} \mathrm{ha}^{-1}$ de lodo de esgoto. ${ }^{*}$ significativo em nível de $5 \%$ de probabilidade; ${ }^{\text {NS }}$ não significativo pelo teste F.

os tratamentos com lodo de esgoto (T5 e T6) foram os que proporcionaram maior valor de matéria orgânica dentre os tratamentos de recuperação (T3 a T6), atingindo valores próximos do limite considerado como teor médio, que é de 15 a $30 \mathrm{Mg} \mathrm{dm}^{-3}$, segundo LOPES (1984). Na camada subjacente $(0,05-0,10 \mathrm{~m})$ do solo foi observada em menor intensidade essa mesma tendência. Estes resultados se assemelham aos encontrados por MELO et al. (2004) e DE MARIA et al. (2007), pois eles observaram que a aplicação de lodo de esgoto aumenta o conteúdo de matéria orgânica apenas na camada superficial do solo $(0,00-0,10 \mathrm{~m})$. É lícito supor que o conteúdo de matéria orgânica do solo continue a aumentar com o passar nos anos, pois ALVES \& SOUZA (2008) verificaram que as técnicas adotadas para recuperação dos atributos do solo no primeiro ano atingiram a profundidade superficial e, somente após cinco anos, a profundidade de 0,00-0,20m.

Os teores de matéria orgânica encontrados são ainda considerados baixos quando se compara à condição natural desse solo não degradado, devido provavelmente à degradação do lodo de esgoto durante os três anos após aplicação (Tabela 2). Isso concorda com os resultados obtidos por CAMILOTTI et al. (2006) os quais verificaram que o teor de matéria orgânica do solo não aumentou mesmo com aplicações que se acumularam ao longo de quatro anos, $51 \mathrm{Mg} \mathrm{ha}^{-1}$ de lodo.

Para as profundidades de 0,00-0,05 e 0,05$0,10 \mathrm{~m}$, observa-se que houve diferença significativa para o contraste entre o tratamento Cerrado e os demais $\left(T_{1}\right.$ $v s$ demais) para a estabilidade de agregados (Tabela 3). Tal fato se deve, provavelmente, aos maiores teores de matéria orgânica presentes nessa área, já que têm atuação primordial na formação e estabilização de agregados (OLIVEIRA et al., 2008).

O tratamento com solo exposto diferiu dos tratamentos cultivados com ou sem aplicação de adubo químico ou lodo de esgoto para a estabilidade de agregado ( $\mathrm{T}_{2} v s$ demais), nas profundidades de 0,00 0,05 e na de $0,05-0,10 \mathrm{~m}$ (Tabela 3 ), indicando que a 
aplicação de lodo de esgoto, fertilizantes e o cultivo de braquiária estão promovendo a recuperação desta propriedade no solo degradado (Tabela 2). ALBIACH (1997) verificou maior estabilidade de agregados com a aplicação de 24,0Mg ha-1 ano $^{-1}$ de lodo de esgoto durante cinco anos.

Nas profundidades de 0,10-0,20 e 0,20-0,30m, não houve incremento significativo para a estabilidade de agregados entre o solo exposto e o solo sob cultivo com ou sem aplicação de adubo mineral ou lodo de esgoto, concordando com os menores valores de matéria orgânica (Tabelas 2 e 3) e com os resultados obtidos por SOUZA et al. (2005) e DE MARIA et al. (2007), os quais, estudando a agregação do solo em área que recebeu lodo de esgoto, verificaram maior estabilidade de agregados somente na camada superficial. DEBOSZ et al. (2002) observaram aumento da estabilidade de agregados na camada superficial de um solo arenoso com a aplicação de $4,2 \mathrm{Mg} \mathrm{ha}^{-1}$ de lodo de esgoto, mas este efeito foi transiente e não permaneceu após 3 anos.

Para a retenção de água nas tensões de 50, 100 e $200 \mathrm{kPa}$, para todas as profundidades estudadas, $\mathrm{o}$ sistema de cerrado diferiu dos demais tratamentos $\left(\mathrm{T}_{1} v s\right.$ demais). Devido à maior quantidade de poros, a retenção de água neste sistema é menor em decorrência da maior movimentação de água (Tabela 3). Os autores BEUTLER et al. (2002) observaram, em área de mata com alto teor de matéria orgânica, menor retenção de água em todas as tensões estudadas, comparada com áreas cultivadas, explicando que a granulometria, a porosidade do solo e a densidade do solo têm maior influência sobre a retenção de água do que o teor de matéria orgânica.

Os tratamentos de recuperação não estão sendo eficazes na estruturação do solo degradado, pois proporcionaram maiores valores médios de retenção de água (Tabelas 3 e 4). Essa maior retenção está relacionada com a compactação do solo, que reduz a

Tabela 4 - Valores médios de teor de água do solo $\left(\mathrm{m}^{3} \mathrm{~m}^{-3}\right)$ retida às tensões de 50,100 e 200kPa para os tratamentos estudados nas camadas de $0,00-0,05 ; 0,05-0,10 ; 0,10-0,20$ e $0,20-0,30 \mathrm{~m}$.

\begin{tabular}{|c|c|c|c|c|}
\hline \multirow{2}{*}{ Tratamentos } & \multicolumn{4}{|c|}{ 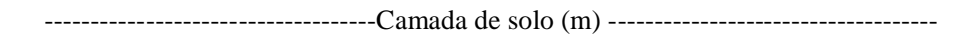 } \\
\hline & $0,00-0,05$ & $0,05-0,10$ & $0,10-0,20$ & $0,20-0,30$ \\
\hline & \multicolumn{4}{|c|}{ 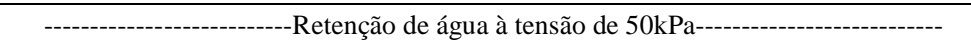 } \\
\hline $\mathrm{T}_{1}$ - Cerrado & 0,12 & 0,12 & 0,11 & 0,11 \\
\hline $\mathrm{T}_{2}$ - Solo exposto & 0,16 & 0,17 & 0,18 & 0,18 \\
\hline $\mathrm{T}_{3}$ - Solo s/ adubação & 0,15 & 0,15 & 0,17 & 0,15 \\
\hline $\mathrm{T}_{4}$ - Ad. mineral & 0,13 & 0,15 & 0,15 & 0,16 \\
\hline $\mathrm{T}_{5-} 30 \mathrm{Mg} \mathrm{ha}^{-1}$ & 0,16 & 0,16 & 0,16 & 0,18 \\
\hline $\mathrm{T}_{6-} 60 \mathrm{Mg} \mathrm{ha}^{-1}$ & 0,16 & 0,16 & 0,16 & 0,16 \\
\hline \multirow[t]{2}{*}{$\mathrm{CV}(\%)$} & 19,62 & 14,71 & 7,38 & 9,41 \\
\hline & \multicolumn{4}{|c|}{ 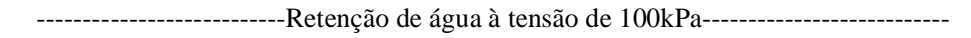 } \\
\hline $\mathrm{T}_{1}$ - Cerrado & 0,11 & 0,11 & 0,10 & 0,10 \\
\hline $\mathrm{T}_{2}$ - Solo exposto & 0,15 & 0,15 & 0,17 & 0,17 \\
\hline $\mathrm{T}_{3}$ - Solo s/ adubação & 0,13 & 0,13 & 0,16 & 0,14 \\
\hline $\mathrm{T}_{4}$ - Ad. mineral & 0,12 & 0,13 & 0,14 & 0,14 \\
\hline $\mathrm{T}_{5-30 \mathrm{Mg} \mathrm{ha}^{-1}}$ & 0,13 & 0,14 & 0,14 & 0,15 \\
\hline $\mathrm{T}_{6-6} 60 \mathrm{Mg} \mathrm{ha}^{-1}$ & 0,12 & 0,15 & 0,14 & 0,14 \\
\hline \multirow[t]{2}{*}{$\mathrm{CV}(\%)$} & 12,62 & 14,39 & 7,07 & 7,53 \\
\hline & \multicolumn{4}{|c|}{ 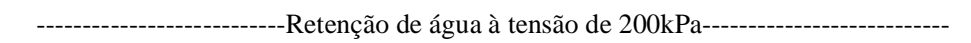 } \\
\hline $\mathrm{T}_{1}$ - Cerrado & 0,10 & 0,10 & 0,09 & 0,10 \\
\hline $\mathrm{T}_{2}$ - Solo exposto & 0,13 & 0,14 & 0,15 & 0,15 \\
\hline $\mathrm{T}_{3}$ - Solo s/ adubação & 0,12 & 0,12 & 0,15 & 0,14 \\
\hline $\mathrm{T}_{4}$ - Ad. mineral & 0,11 & 0,12 & 0,13 & 0,14 \\
\hline $\mathrm{T}_{5-} 30 \mathrm{Mg} \mathrm{ha}^{-1}$ & 0,12 & 0,13 & 0,13 & 0,14 \\
\hline $\mathrm{T}_{6-} 60 \mathrm{Mg} \mathrm{ha}^{-1}$ & 0,11 & 0,13 & 0,13 & 0,14 \\
\hline $\mathrm{CV}(\%)$ & 10,76 & 15,65 & 8,47 & 8,62 \\
\hline
\end{tabular}

$\mathrm{T}_{1}$ - vegetação natural de Cerrado; $\mathrm{T}_{2}$ - solo degradado, sem tratamento para recuperação; $\mathrm{T}_{3}$ - solo degradado, cultivado com eucalipto e braquiária, sem aplicação de lodo de esgoto e adubo mineral; $\mathrm{T}_{4}$ - solo degradado, cultivado com eucalipto e braquiária com adubação mineral de acordo com a necessidade da cultura e a análise do solo; $\mathrm{T}_{5}$ - solo degradado, cultivado com eucalipto e braquiária com uso de $30 \mathrm{mg} \mathrm{ha}^{-1}$ de lodo de esgoto (base seca); $\mathrm{T}_{6}$ - solo degradado, cultivado com eucalipto e braquiária com uso de $60 \mathrm{mg}^{-1}$ de lodo de esgoto (base seca).

Ciência Rural, v.41, n.5, mai, 2011. 
macroporosidade e a porosidade total, além de aumentar a densidade, a microporosidade e a capacidade de retenção de água do solo. MELO et al. (2004), estudando o efeito da aplicação de lodo de esgoto em atributos físicos de Latossolos, não observaram diferenças na retenção de água, em todas as tensões e profundidades, até a dose de 50,0 $\mathrm{Mg} \mathrm{ha}^{-1}$ de lodo de esgoto.

Para o contraste do $\mathrm{T}_{3}$ vs demais, que compara o tratamento com o solo cultivado com eucalipto sem adubação (mineral ou orgânica) com os tratamentos com solo cultivado com eucalipto mais adubação mineral ou adubação orgânica (Tabela 3), não houve diferença para todos os atributos físicohídricos estudados, demonstrando que o cultivo de eucalipto e braquiária tem o mesmo efeito da adubação para estes atributos. O mesmo comportamento está ocorrendo para os contrastes entre os tratamentos de recuperação com aplicação de diferentes doses de lodo de esgoto $\left(\mathrm{T}_{5} v s \mathrm{~T}_{6}\right)$. Resultados semelhantes foram observados por DE MARIA et al. (2007), para as doses 10 e $20 \mathrm{Mg} \mathrm{ha}^{-1}$ de lodo de esgoto.

\section{CONCLUSÃO}

Os tratamentos com adição de adubação mineral e orgânica estão agindo de forma semelhante para a recuperação dos atributos físico-hídricos e o teor de matéria orgânica, sendo que o lodo de esgoto está sendo mais promissor na camada superficial do solo. Para solos degradados pela construção de obras civis, o lodo é viável na recuperação de suas propriedades físico-hídricas.

\section{REFERÊNCIAS}

ALBIACH, R. Estudio de varios índices de actividad biológica del suelo en relación a diferentes aportaciones de enmiendas organicas. Valencia: University of Valencia Publishing Service, 1997. 190p.

ALVES, M.C. et al. Densidade do solo e infiltração de água como indicadores da qualidade física de um latossolo vermelho distrófico em recuperação. Revista Brasileira de Ciência do Solo, Viçosa, v.31, n.4, p.617-625, 2007.

ALVES, M.C.; SOUZA, Z.M. Recuperação de área degradada por construção de hidroelétrica com adubação verde e corretivo. Revista Brasileira de Ciência do Solo, Viçosa, v.32, n.6, p.2505-2516, 2008.

ANDRADE, C.A. at al. Qualidade da matéria orgânica e estoques de carbono e nitrogênio em latossolo tratado com biossólido e cultivado com eucalipto. Revista Brasileira de Ciência do Solo, Viçosa, v.29, n.5, p.803-816, 2005.
ANGERS, D.A.; MEHUYS, G.R. Aggregate stability to water. In: CARTER, M.R. Soil sampling and methods of analysis. Boca Raton: Canadian Society of Soil Science, 1993. p. 651-657.

BEUTLER, A.N. et al. Retenção de água em dois tipos de latossolos sob diferentes usos. Revista Brasileira de Ciência do Solo, Viçosa, v.26, n.3, p.829-834, 2002.

BEZERRA, F.B. et al. Lodo de esgoto em revegetação de área degradada. Pesquisa Agropecuária Brasileira, Brasília, v.41, n.3, p.469-476, 2006.

CAMILOTTI, F. et al. Atributos físicos de um latossolo cultivado com cana-de-açúcar após aplicações de lodo de esgoto e vinhaça. Engenharia Agrícola, Jaboticabal, v.26, n.3, p.738-747, 2006.

DEBOSZ, K. et al. Evaluating effects of sewage sludge and household compost on soil physical, chemical and microbiological properties. Applied Soil and Ecology, Amsterdam, v.19, n.3, p.237-248, 2002. Disponível em: <http://www.sciencedirect.com/ science?_ob=PublicationURL\&_tockey=\%23TOC $\% 234970 \% 232$ $002 \% 23999809996 \% 23284928 \% 23$ FLA\%23\&_cdi=4970\&_ pubType=J\&_auth=y\&_acct $=C 000049647 \& \_$version=1 \&_url Version $=0 \& \_$userid $=972052 \& \mathrm{md} 5=65 \mathrm{bc} 3 \mathrm{~b} 49 \mathrm{de} 7 \mathrm{~d} 538 \mathrm{a} 05 \mathrm{e} 0 \mathrm{~b} 7$ ff7ed4dffb>. Acesso em: 20 fev. 2011. doi: 10.1016/S09291393(01)00191-3.

DE MARIA, I.C. et al. Agregação do solo em área que recebeu lodo de esgoto. Bragantia, Campinas, v.66, n.2, p.291-298, 2007.

DEMATTÊ, J.L.I. Levantamento detalhado dos solos do "Campus Experimental de Ilha Solteira". Piracicaba: Escola Superior de Agricultura Luiz de Queiroz, 1980. 44p.

EMPRESA BRASILEIRA DE PESQUISA AGROPECUÁRIA EMBRAPA. Centro Nacional de Pesquisa de Solos. Manual de métodos de análise de solo. 2.ed. Rio de Janeiro: Embrapa/ Centro Nacional de Pesquisa de Solos, 1997. 212 p.

EMPRESA BRASILEIRA DE PESQUISA AGROPECUÁRIA EMBRAPA. Centro Nacional de Pesquisa de Solos. Sistema Brasileiro de Classificação de Solos. Rio de Janeiro, 2006. $306 \mathrm{p}$.

KITAMURA, A.E. et al. Recuperação de um solo degradado com a aplicação de adubos verdes e lodo de esgoto. Revista Brasileira de Ciência do Solo, Viçosa, v.32, n.1, p.405416, 2008.

LOPES, A.S. Solos sob “cerrados": características, propriedades e manejo. Piracicaba: Instituto da Potassa \& Fosfato: Instituto Internacional da Potassa, 1984. 162 p.

MELO, V.P. et al. Atributos físicos de Latossolos adubados durante cinco anos com biossólido. Pesquisa Agropecuária Brasileira, Brasília, v.39, n.1, p.67-72, 2004.

MELO, W.J. et al. Efeito de doses crescentes de lodo de esgoto sobre frações da matéria orgânica e CTC de um Latossolo cultivado com cana-de-açúcar. Revista Brasileira de Ciência do Solo, Campinas, v.18, p.449-455, 1994.

OLIVEIRA, J.T. et al. Características físicas e carbono orgânico de solos sob diferentes tipos de uso da terra. Revista Brasileira de Ciência do Solo, Viçosa, v.32, p.2821-2829, 2008. 
PALADINI, F.L.S.; MIELNICZUK, J. Distribuição de tamanho de agregados de um solo Podzólico Vermelho-Escuro afetado por sistema de culturas. Revista Brasileira de Ciência do Solo, Campinas, v.15, p.135-140, 1991.

RICHARDS, L.A. Physical condition of water in soil. In: BLACK, C.A. et al. (Ed.). Methods of Soil Analysis. Madison: American Society of Agronomy, 1965. p.128-151.

SOUZA, Z.M. et al. Estabilidade de agregados e resistência à penetração em Latossolos adubados por cinco anos com biossólido. Revista Brasileira de Ciência do solo, Viçosa, v.29, n.1, p.117-123, 2005.

TRANNIN, I.C.B. et al. Atributos químicos e físicos de um solo tratado com biossólido industrial e cultivado com milho. Revista Brasileira de Engenharia Agrícola e Ambiental, Campina Grande, v.12, n.3, p.223-230, 2008.

VAZ, L.M.S.; GONÇALVES, J.L.M. Uso de biossólidos em provoamento de eucalipto; efeito em atributos químicos do solo, no crescimento e na absorção de nutrientes. Revista Brasileira Ciência Solo, v.26, p.747-758, 2002. 